\title{
Acceptance of Game-Based Learning and Intrinsic Motivation as Predictors for Learning Success and Flow Experience
}

\author{
Manuel Ninaus ${ }^{1,2^{*}}$, Korbinian Moeller ${ }^{1,2,3}$, Jake McMullen ${ }^{4}$, Kristian Kiili ${ }^{5}$ \\ ${ }^{1}$ Leibniz-Institut für Wissensmedien, Tuebingen, Germany, \\ \{m.ninaus,k.moeller\}@iwm-tuebingen.de \\ ${ }^{2}$ LEAD Graduate School, Eberhard-Karls University, Tuebingen, Germany \\ ${ }^{3}$ Department of Psychology, Eberhard Karls University, Tuebingen, Germany \\ ${ }^{4}$ Centre for Learning Research, University of Turku, Turku, Finland, jamcmu@utu.fi \\ ${ }^{5}$ TUT Game Lab, Tampere University of Technology, Pori, Finland, kristian.kiili@tut.fi
}

\begin{abstract}
There is accumulating evidence that engagement with digital math games can improve students' learning. However, in what way individual variables critical to game-based learning influence students' learning success still needs to be explored. Therefore, the aim of this study was to investigate the influence of students' acceptance of game-based learning (e.g., perceived usefulness of a game as a learning tool, perceived ease of use), as well as their intrinsic motivation for math (e.g., their math interest, self-efficacy) and quality of playing experience on learning success in a game-based rational number training. Additionally, we investigated the influence of the former variables on quality of playing experience loperationalized as perceived flow). Results indicated that the game-based training was effective. Moreover, students' learning success and their quality of playing experience were predicted by measures of acceptance of game-based learning and intrinsic motivation for math. These findings indicated that learning success in game-based learning approaches are driven by students' acceptance of the game as a learning tool and content-specific intrinsic motivation. Therefore, the present work is of particular interest to researchers, developers, and practitioners working with gamebased learning environments.
\end{abstract}

Keywords: technology acceptance, intrinsic motivation, user experience, math game, rational numbers, game-based learning;

\section{Introduction}

Digital games are a ubiquitous part in our everyday life. Be it on your own smartphone, console or your personal computer. Recently, however, there is an increase of research interest into games in educational practice reflected by terms such as game-based learning, educational games or serious games. These educational tools have the potential to provide engaging, motivating and interactive learning environments and thus promote learning outcomes. In primary and secondary education in particular, game-based learning provides a promising approach to engage students in acquiring knowledge, initiating behavioural change and content understanding, just to name a few outcomes (for a review see [1]). According to [1], games seem to be most popular in the domain of mathematics instruction. Nevertheless, [2] argued that while it is easy to find digital games for learning mathematics, only very few of these existing games are based on theoretically sound principles, integrate mathematics directly into the gameplay, rely on good pedagogical practices, and exploit possibilities that game technologies provide for learning. In fact, [2] concluded that to date only a few existing mathematics games indeed focus on developing numerical cognition and mathematical thinking.

In this vein, the current study employed a game for teaching mathematics based on most recent developments in research on numerical cognition. In particular, we used the Semideus 
research engine, which was already used successfully to assess students' rational number knowledge (e.g., [3][4]). The present study extends the scope of these articles by evaluating possible influence of individual factors such as intrinsic motivation for math (i.e., math interest and math self-efficacy) but also game-related individual variables on the acceptance of gamebased learning (e.g., perceived usefulness of games) and quality of playing experience on learning success with the employed game.

In the following, we will first give a brief overview regarding the use of games in math learning and the presumable role of self-efficacy and math interest, as predecessors and determinants of intrinsic motivation, on learning outcomes. After that, we briefly introduce ideas on the acceptance of games as a learning tool and the experienced quality of game play as assessed by the experienced flow during playing.

\subsection{Games in math learning}

Because of the importance and relevance of primary and early secondary mathematics education as building blocks for later mathematics achievement, the existing popularity of math games is not surprising. More importantly, however, computer-supported approaches on math learning (including math games) seem to be effective in teaching students and some of them produce even better effects than conventional approaches or paper-based approaches (see [5][6] for a review). As such, positive effects of digital game-based learning have been shown in different areas of mathematics, such as the understanding of number magnitude (e.g., [7][8]), basic arithmetic operations (e.g., [9]), solving simple equations (e.g. [10]), etc. Taken together, digital games for learning are not only popular in the domain of mathematics education but also seem to be effective.

In the present study, we based the core gameplay of the employed Semideus research engine on the mechanic of a number line estimation task because this task has been shown repeatedly to provide meaningful measures of children's numerical competences as well as to be effective as a training tool to foster children's understanding of whole number (e.g., [11]) but also fraction magnitude (e.g., [3][12]). More specifically, the number line estimation task requires players to map numbers onto space. For instance, they are shown a horizontal line with specified start and endpoints (e.g., 0 and 1) and asked to estimate the position of a given target number on the line (e.g. $2 / 3$ or 0.75 ; e.g., [12]). Importantly, performance in the number line estimation task is not only associated with actual and predictive of future arithmetic performance (e.g., [11]) but recent studies demonstrated that it is associated also with children's understanding of number magnitude (e.g., [13][14]). This makes it a perfect candidate for a basic game mechanic (for more details on the employed game see 2.2). Accordingly, the design of the employed game was based on recent developments in numerical cognition research (e.g., [15] for a review on rational number knowledge; for more details on the theoretical foundations of Semideus see also [3]).

As regards the employment of digital games in educational contexts, it is obvious that one of the aims for doing so is increasing the enjoyment of students during learning. And indeed, as a medium for learning, games or game-based environments provide promising possibilities to motivate and engage students in learning (e.g., [16]). In fact, even simple game-like extrinsic motivators, such as score points, can increase enjoyment in learning but also simple cognitive tests (e.g. [17]; for a review see [18]). However, in the present study we specifically aimed at investigating the potential effect of intrinsic motivation or interest in mathematics [19], respectively, on learning success in a game-based environment. This should allow for examining whether interest in the learning domain is still a relevant predictor of learning even in an enjoyable game-based learning environment. This seems particularly relevant because intrinsically motivated individuals may not require extraneous incentives to learn [19]. In this context, the feeling of competence or self-efficacy during an activity needs to be considered as it is an important predecessor of intrinsic motivation because it allows for satisfying the basic psychological need for competence [19][20]. Importantly, it has been long known and consistently been demonstrated that math self-efficacy predicts math related performance in traditional school settings (e.g. [21-25]).

\subsection{Acceptance of games as a tool for learning}

In recent years, increasing research interest has been devoted to the role of games and game elements as a tool for learning (for a reviews see [1][26]). As a consequence, teachers and parents now become also more aware of this new learning approach. However, successful employment of such new and innovative learning approaches requires high levels of acceptance or perceived 
usefulness by the involved individuals. Currently, teachers often still lack experience with games for learning or with video games in general (e.g., [27-29]). However, recent studies indicated that they nevertheless think that games can provide opportunities for learning [29]. Parents also seem not ass experienced with video games and thus are rather indifferent about the employment of games for learning [30]

Most important for learning outcomes, however, may be the acceptance of children as the actual learners. Initial acceptance cannot be taken for granted in children, as some hold the (false) belief that playing games is in fact irrelevant for learning [10][31][32]. However, because children are the ones most affected by introducing games for learning, acceptance of game-based learning in children may be a crucial factor for learning success. According to the technology acceptance model (TAM) [33], a prevailing theory to predict adoption of technologies (e.g., [29][30][32][3437]), acceptance of any technology can be predicted by (i) the users' perceived usefulness, as well as (ii) the ease of use of a given technology, in our case the learning game. Therefore, in the current study, we aimed at investigating whether students' acceptance of our game, its ease of use as well as their beliefs about the usefulness of it as a learning tool were associated with their learning success.

\subsection{Quality of the playing experience}

Another critical factor not only for the acceptance but also the learning outcomes of a serious game might be the overall quality of the playing experience (henceforth referred to as flow). This is particularly important, when intending that students will use games for learning not only in school but also in their leisure time as an intrinsically motivated learning experience. In this context, flow experience as a state of peak enjoyment is one of the central indicators for engaging playing experiences (e.g., [38][39]), often also referred to as optimal experience [40]. Generally, enjoyment or flow level is a key factor for determining whether players will be engaged in the gameplay, perform according to their skills, and achieve the objectives of the game [41]. Moreover, students' enjoyment of learning was observed to be correlated positively with their academic achievement [42]. Flow, in particular, is a complex construct describing a state of complete absorption and engagement in a specific activity. In a state of flow, task-irrelevant thoughts and emotions are prevented, enhancing attention on task relevant actions and thereby improving performance [43][44]. During this experience, players are in a positive psychological state and totally involved in the goal-driven activity. Persons perceiving this experience are often willing to perform a given activity for its own sake, without being concerned whether they get any external rewards out of this activity. This kind of intrinsic motivation is particularly relevant in (game-based) learning. Against this background, games for learning may be expected to be more effective than non-game based equivalents in terms of enjoyment and flow - possibly also increasing learning outcomes (e.g. [17][45]; for a reviews see [18][46][47]).

\subsection{Present study and hypotheses}

In the current study we address one of most challenging problems in primary level mathematics education, the learning and understanding of rational numbers (e.g., [48]). In fact, dealing with decimals and fractions seems crucial in mathematics education because mastery of the concept of rational numbers is required in more advanced mathematical topics such as algebra. In line with this, it was repeatedly observed that high school students' fraction knowledge highly correlates with their actual mathematics achievement but also predicts future algebra and overall mathematics achievement in high school significantly (e.g., [3][49][50]).

Therefore, we specifically aimed at improving students' rational number knowledge, as one of the most crucial elements for math achievement (e.g. [50]), using a game-based approach based on number line estimation. Apart from the effectiveness of a short-term game-based training the current study paid specific attention to aspects of user acceptance and their intrinsic motivation, because these seem crucial when introducing a new learning approach. In particular, we were interested whether these player variables influenced learning success but also the experienced flow when playing the game.

Based on above review of recent evidence on learning mathematics, game-based learning, and the aforementioned aspects of acceptance and intrinsic motivation, we derived the following hypotheses: First, the game-based training should significantly improve players' knowledge of rational numbers (Hypothesis 1). Moreover, we expected that this improvement in rational number knowledge due to our game-based training should be associated positively with students' 
acceptance of the employed game, their general intrinsic motivation doing mathematics (math interest \& self-efficacy), and their flow experience during playing (i.e., quality of playing experience; Hypothesis 2). Finally, we expected a positive association of students' flow experience (i.e., quality of playing experience) and students' acceptance of the employed game and their intrinsic motivation (Hypothesis 3).

\section{Method}

\subsection{Participants}

32 sixth graders participated in the study. Participants were from one Finnish public primary school. Of the students 19 were females, 13 males. Mean age of the students was 11.94 years $(S D$ $=.35$ years). Math achievement was measured by students' previous math grade (following the Finnish classification scheme 10 reflects the best and 4 the lowest grade; $M=8.66 ; S D=.94$ ).

\subsection{Description of the Semideus School game}

We modified the Semideus Exam game that we recently used for assessing students' rational number knowledge [3][51] to better fit for training purposes. Comparable to the exam version, the gameplay of the new Semideus School game was founded on tasks that require working with number lines implemented as walkable platforms of a mountain including estimating, comparing and ordering tasks (see [3] for a description of the game or https://youtu.be/dVatjMkk0_I for a gameplay video). In the number line estimation tasks of the Semideus School game the player had to find gold coins on a number line with their position indicated by a given number. Additionally, the player faced tasks in which she/he had to compare and order rational numbers according to their magnitudes by putting stones in the correct order (Figure 1).

In order to increase learning effectiveness of the game and the quality of the playing experience we utilized the flow framework for educational games [39] in the redesign process. In particular, we focused on clear goals, immediate feedback, challenge-skill balance, and playability dimensions contributing to the flow state.

With respect to playability of the game, we implemented the tutorial phase in a way that a player can not complete the tutorial world without understanding how all the game controls and mechanics work. We divided the main goal, completing the whole Semideus game, into clear subgoals that can be performed at appropriate pace leading to sequence of success feelings. With respect to the challenge-skill balance dimension the difficulty level of the tasks was gradually increased according to player's progress in the game. The flow channel was extended by providing some guidance to the players through scaffolding features. For example, when players repeatedly fail in number line estimation and thereby lose virtual energy (health bar), the game engine provides graphical and numerical landmarks. Additionally, the game engine provides bar chart visualizations that support the understanding of magnitudes in comparison and ordering tasks. Moreover, players may use diamonds (in-game currency) that he/she can gather during the game to demand help from playing companions, a goat and a bird. In estimation tasks, the goat would show the right location of the coin cache to players. In comparison tasks the bird would expand or reduce the fractions so that they have same denominators.

The game engine also generates personal hints for players illustrating identified misconceptions accompanied with links to game levels addressing identified misconceptions. Additionally, players can track his or her performance on a personalized statistics/analytics page. Accuracy on different kinds of number line estimation, comparison, and ordering tasks are illustrated with charts. 

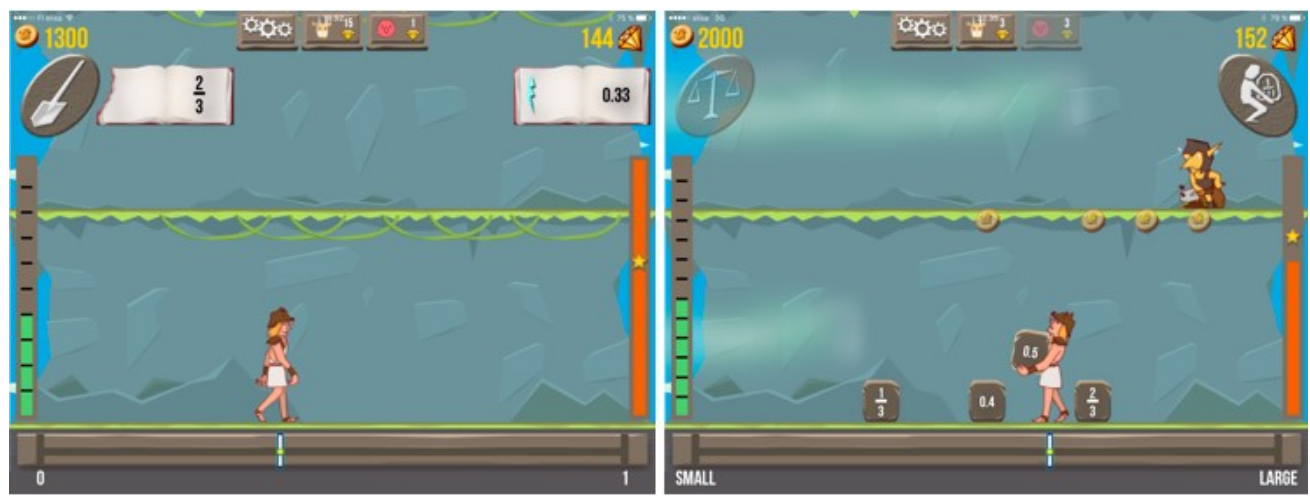

Figure 1. Left chart: An example of a number line estimation task in which the player should dig up a coin cache at the location reflecting $2 / 3$ and avoid a trap at location $1 / 3$. Right chart: An example of an ordering task including both fractions and decimals; orange bar on the right side of the screen reflected the health bar that shows how much virtual energy is left

\subsection{Procedure}

During a one-week period, students played the Semideus School game for approximately 2 hours (4 playing sessions of about 30 minutes each). Students were allowed to freely play the game during the sessions with their iPads.

The Semideus School game used in the present study consisted of 59 levels focusing on rational number knowledge (number line estimation, magnitude comparison, and magnitude ordering tasks). The levels of the game were divided into eight game worlds: 1 Tutorial trails, 2 Show your skills I (pretest in the present study), 3 Lesson trails, 4 Beginner trails, and 5 Show your skills II (posttest in the present study). Further game worlds, i.e. 6 Intermediate trails, 7 Show your skills III, and 8 Expert trails, were implemented in the game for students who were progressing faster than others in order to provide them the possibility to keep playing, improve their skills further on, and to not disturb the other students. After completing a level (reaching the mountaintop) the player earned 1 to 3 stars (i.e., one star for completing the level, one star for collecting enough coins, and one star from accuracy or performance reflecting that enough energy was left). In order to open the next game world, players had to pass each level of the current world and achieve $60 \%$ of the stars of the world.

The pretest and the posttest levels could be played only once. Although a player could activate different kind of scaffolding features and aids by using earned diamonds in the basic levels, it was not possible in the test levels. The test levels did not include either numerical or graphical landmarks. Furthermore, unlike the basic levels, the test levels were configured in a way that players could not die at all (i.e. running out of virtual energy), but always completed the test levels.

Students were told that they are expected to complete at least the first 30 levels. In that way, we got pre- and posttest scores from all students. At first, students completed the tutorial world and the pretest world. After the pretest, students played through two game worlds that included altogether 20 levels (200 tasks). Once the students completed the posttest and completed the last playing session they answered the questionnaires of the current study.

A researcher instructed all playing sessions and wrote down observation notes about students playing experiences and playing behaviour. The researcher also discussed with the students about the implementation of the game and students' playing experiences.

\subsection{Measures}

\subsubsection{Measures related to mathematics}

Pre- and posttest

Pre- and posttests were embedded directly into the game and the game recorded players answers to a secured server. Both in-game pretest and in-game posttest consisted of 10 estimation tasks (number line 0-1) from which five were fraction number tasks and the rest were decimal number tasks, 10 estimation tasks (number line 0-5) from which five were fraction number tasks and the rest were decimal number tasks, 10 fraction and decimal comparing tasks, and 13 fraction and 
decimal number ordering tasks. Comparing and ordering tasks were designed to address the most common rational number misconceptions. Pre- and posttest were evaluated in terms of the correctness of all performed tasks. Estimation correctness of 0 to 1 number line tasks was based on $+-8 \%$ error limit and 0 to 5 number line tasks on $+-10 \%$ error limit. Effectiveness of the training was measured with the gain from pre- to posttest (learning success: [posttest score] - [pretest score]).

\section{Intrinsic motivation}

Intrinsic motivation was measured with self-reported measures of math interest and math selfefficacy. The employed items were framed specifically for mathematics, which allowed to examine intrinsic motivation for the content domain of the employed game. Specifically, items used to measure math interest and math self-efficacy were adopted from [52]. Previous studies have identified (math) self-efficacy and (math) interest as important predecessors and determinants of intrinsic motivation [19-25]. Math interest was measured by three items and math self-efficacy was measured by three items using 5-point Likert-scales (ranging from $1=$ totally disagree to $5=$ totally agree).

\section{Math grade}

Math grade was determined by participants' previous math grade in school (following the Finnish classification scheme 10 reflects the best and 4 the lowest grade). Participants' teacher provided the math grades.

\subsubsection{Measures related to game-based learning}

\section{Acceptance of the game as a learning tool}

The questions measuring acceptance of the game as a learning tool were derived from dimensions of the Technology Acceptance Model [33]. We evaluated acceptance with the Perceived usefulness, Intention to use, and Perceived ease of use dimensions. The first question addressed the perceived usefulness dimension by asking students' opinion on whether they think that the game may be effective in teaching ("I believe that one can learn math by playing the Semideus game."). The second question addressed the intention to use dimension by asking students whether they would generally prefer game-based over paper-pencil-based training ("I would like to train fraction and decimal numbers by playing the Semideus game rather than doing exercises of a math book."). The third question addressed the perceived ease of use dimension by asking students how easy it was to control the game character ("The controlling of the game character was easy."). A 6point Likert-scale was used (ranging from $1=$ totally disagree to $6=$ totally agree).

Quality of playing experience - flow

Students' quality of playing experience was evaluated in terms of flow experience [39][44]. The level of experienced flow during playing the game was measured directly after the last training session with a modified version of the Flow Short Scale [53]. The Flow Short Scale measures flow experience with ten items (7-point Likert- scale ranging from $1=$ totally disagree to $7=$ totally agree). We modified the statements of the scale from present tense to imperfect and added references to game playing activity.

\subsection{Analysis}

To evaluate whether students improved from pre- to post-assessment a paired samples t-test was conducted with mean correctness as dependent variable. To examine the relation between flow, learning success ([posttest score] - [pretest score]), and user variables correlation analyses were run. Four participants were excluded from correlation analyses since they did not answer the questionnaires and ratings. Additionally, two separate forced-entry multiple regression analyses were used to identify user variables predictive of learning success and perceived flow, respectively. Analyses were performed using the statistical-computing language R [54]. Data visualization was realized with the package corrplot [55]. 


\section{Results}

\subsection{Effectiveness of the game-based training}

Using a paired t-test we examined potential improvement in students mean correctness from pre$(M=69 \% ; S E=13 \%)$ to posttest $(M=80 \% ; S E=11 \%)$ assessment, i.e. number line estimations, comparison tasks and ordering tasks performance. As hypothesized (Hypothesis 1), students improved significantly in their rational number knowledge from pre- to posttest $[(t(31)=6.37 ; p<$ .001 ; Cohen's $d=1.13$ ] indicating that our game-based training was effective.

\subsection{Acceptance, intrinsic motivation, and learning success}

As shown in Figure 2, the correlation analysis indicated that "perceived usefulness" ( $r=.41$, medium-sized effect according to the classification of [56], pp. 79-80), "intention to use" ( $r=.55$, large effect) and "perceived ease of use" ( $r=.39$, medium-sized effect, i.e., acceptance of the employed game) correlated positively with learning success, suggesting that variables related to accepting games for teaching/learning and Semideus in particular were associated with students' improvement in rational number knowledge.

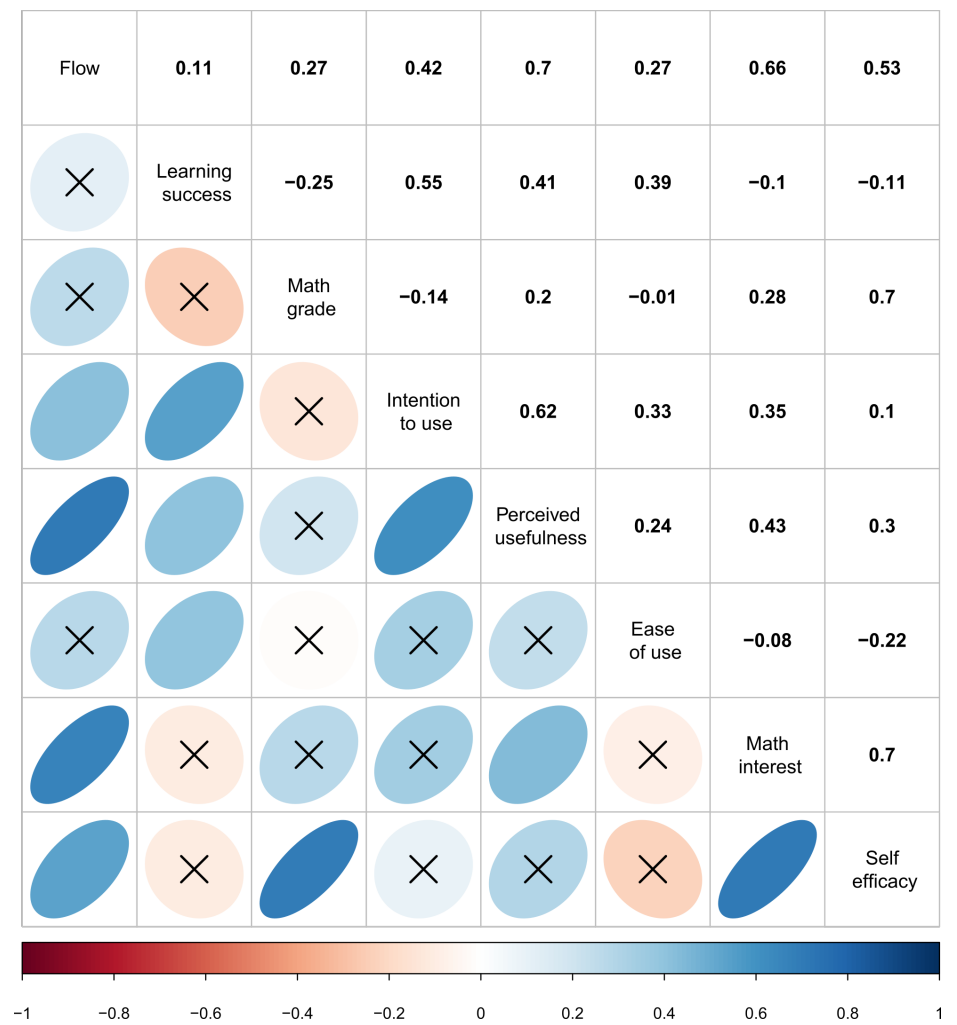

Figure 2. The upper triangular matrix depicts the correlation coefficients between learning success, math and game based learning related measures; in the lower triangular positive/negative correlations are illustrated with blue/red colours. Crosses indicate non-significant correlations $(\mathrm{p} \geq$ $.05)$.

In a second step, we examined whether variables of acceptance (perceived usefulness; intention to use, perceived ease of use), intrinsic motivation (math interest, self-efficacy), experienced flow, and math grade may be predictive for students' improvement from pre- to posttest (Hypothesis 2). Therefore, we used the learning success as dependent variable and the following user variables as potential predictors in a multiple regression analysis: i) Flow; ii) Self-efficacy; iii) Math grade; iv) Math interest; v) perceived usefulness; vi) intention to use; vii) perceived ease of use. The forcedentry multiple regression model explained $61 \%$ of variation in learning success, [i.e., performance improvement from pre- to posttest assessment, $F(7,20)=4.39, p<.01$, adj. $\left.R^{2}=0.47\right]$. The result indicated a medium-sized effect considering adjusted $\mathrm{R}^{2}$ (following the classification of [56], 
pp.413-414). Results of the regression analysis indicated that perceived usefulness, perceived ease of use, self-efficacy, math interest, math grade were significant predictors of learning success (see Table 1). Inspection of the beta weights indicated that higher improvement in rational number knowledge was predicted by students' perceiving Semideus as useful and easy to use. Importantly, while higher math self-efficacy predicted higher improvement in rational number knowledge, the same was true for lower math grades and lower math interest. Flow (unstandardized $\beta=-.038$, standardized $\beta=-.403$, n.s.) and intention to use (unstandardized $\beta=.014$, standardized $\beta=.272$, n.s.) did not account for a unique part of the variance of rational number knowledge improvement from pre- to posttest. In order to better understand the negative relation between math grades and learning success a correlation analysis was run, which yielded a rather strong positive relation between these two variables $(r=.65, p<.001)$. This shows that students with better math grades performed already better in the pretest assessing rational number knowledge.

\subsection{Acceptance, intrinsic motivation, and flow}

To evaluate how well individual user variables reflecting students' acceptance of game-based learning, intrinsic motivation, math self-efficacy were associated with students perceived flow experience correlation analyses were run as a first step. As shown in Figure 2, intention to use $(r=$ .42 , medium-sized effect), perceived usefulness $(r=.7$, large effect), math interest $(r=.66$, large effect) as well as math self-efficacy ( $r=.53$, large effect) correlated positively with flow, indicating that players' acceptance of the game, their intrinsic motivation, and math self-efficacy were related to their perceived flow (for effect size classification see [56], pp. 79-80).

Again, we investigated which of these variables were predictive of students' perceived flow using a forced-entry multiple regression analysis with the flow score as dependent variable and the following user variables as predictors: i) Self efficacy; ii) Math interest; iii) perceived usefulness; iv) intention to use; v) perceived ease of use. The final regression model explained $72 \%$ of variation in participants' perceived flow $\left[F(5,22)=11.13, p<.001\right.$, adj. $\left.R^{2}=0.65\right]$ indicating a large effect size following the recommendation of [56] (pp.413-41). Inspection of the beta weights indicated that, perceived usefulness, ease of use, and math interest were significant predictors (see Table 1). This reflects that higher acceptance of Semideus as a teaching application, perceived ease of use of the game, and higher math interest were accompanied by higher flow experience within the game (Hypothesis 3). Math self-efficacy (unstandardized $\beta=.306$, standardized $\beta=$ .189 , n.s.) and intention to use (unstandardized $\beta=-.073$, standardized $\beta=-.128$, n.s.) were no significant predictors of students flow experience.

Table 1. Significant predictors of the two multiple regression analyses predicting learning success and flow

\begin{tabular}{l|l|c|c|c|c}
\hline Dependent variable & Significant predictors & Unstandardized $\boldsymbol{\beta}$ & Standardized $\boldsymbol{\beta}$ & $\boldsymbol{R}^{\mathbf{2}}$ & $\mathbf{A d j}^{.} \boldsymbol{R}^{\mathbf{2}}$ \\
\hline Learning success & (Intercept) & .269 & .844 & \\
\hline & Self-efficacy & $.128^{*}$ & -.640 & \\
\hline & Math grade & $-.069^{*}$ & -.545 & \\
\hline & Math interest & $-.055^{*}$ & .531 & \\
\hline & Perceived usefulness & $.033^{*}$ & .417 & \\
\hline & Perceived ease of use & $.024^{*}$ & & .606 & .468 \\
\hline & & & & \\
\hline Flow & & .212 & .382 & \\
\hline & (Intercept) & $.405^{*}$ & .492 & \\
\hline & Math interest & $.165^{*}$ & .268 & \\
\hline & Perceived usefulness & & & .717 & .652 \\
\hline & Perceived ease of use & & & \\
\hline
\end{tabular}

$* p<.05$.

$* * p<.01$.

\section{Discussion}

The goal of the current study was to examine whether individual player variables such as intrinsic motivation in math and acceptance of a game-based math learning tool are predictive of learning success and perceived flow experience. Therefore, we employed and evaluated game-based 
rational number training in sixth graders. Results clearly indicated that post-training self-reports on intrinsic motivation and acceptance of the game as a learning tool were not only predictive of the actual learning success but also the perceived flow. In the following, these results will be discussed in turn and in more detail.

\subsection{Game based training improves rational number knowledge}

In line with recent studies (e.g., [3][12]), we expected to observe improvements in rational number knowledge through number line based training. Significant performance increases from pre- to posttest confirmed our hypothesis (Hypothesis 1). In particular, 20 levels (200 tasks of number line estimation as well as magnitude comparison and ordering involving fractions) of gameplay improved six grade students' rational number knowledge. Importantly, the pre- as well as the posttest was realized within the game-based environment (i.e., learning context was similar to test conditions) to prevent possible context specific learning effects (e.g. [57]). Thereby our data further support the use of games not only for assessing (e.g., [3]) but also for training students' rational number knowledge.

\subsection{Acceptance and intrinsic motivation predict learning success}

Considering the specific goal of the study - the evaluation of aspects of intrinsic motivation and acceptance of game-based learning as predictors of learning success - results were meaningful with medium to large-sized effects. We observed that students who perceived the game as useful for learning mathematics and easy to use improved more strongly with regard to their rational number knowledge (Hypothesis 2; see also Table 1). The most important predictor for students' learning success, however, was their math self-efficacy indicating that students who reported strong beliefs on their ability to perform well in mathematics benefitted more from the training (i.e., showed higher performance increases from pre- to posttest) than students with low reported self-efficacy. Unexpectedly, though, students with higher self-reported interest in math and better math grades were not as successful in improving their rational number knowledge as compared to those with lower interest in math and worse math grades. A post-hoc correlation analysis between math grades and pretest performance indicated that students with better math grades already had higher rational number knowledge than students with lower math grades at pretest. In turn, this means that students with lower rational number knowledge benefitted more from the training. This may be due to the fact that because of their lower pretest performance it was easier for these students to further improve their rational number knowledge as compared to those who already had good rational number knowledge (i.e., it may be easier to increase performance from $50 \%$ correct to $60 \%$ correct as it is to improve from $85 \%$ to $95 \%$ correct). Nevertheless, this may also indicate that game-based learning of rational numbers may be specifically effective for students with lower prior knowledge on the topic.

As with any other new and successful learning technology, acceptance is a critical aspect in achieving large-scale adoption of this technology by potential users. According to the TAM [33] user acceptance and the accompanying belief of performance improvement is predicted by the users' perceived usefulness, as well as the perceived ease of use of the given technology. In the current study, both of these critical variables were observed to be predictive of students' increase in rational number knowledge. In particular, our results indicated that high levels of acceptance of our game-based tool for learning were accompanied by a more pronounced learning success. This is in line with earlier findings of user acceptance factors and (perceived) learning performance in digital learning environments (e.g., [58][59]). Moreover, although intention of use (i.e., actual preference of using game-based learning instead of a conventional math book), was not found to explain a unique part of the variance of learning success, this does not mean that it may not be a relevant factor as well. Importantly, we observed a positive correlation between learning success and intention to use, indicating that the preference of using a game for learning math was indeed positively related to the improvement in rational number knowledge. However, as intention to use was moderately correlated to perceived usefulness and the latter variable was already included in the regression model possible unique influences of intention to use might have been masked.

As regards measures of intrinsic motivation math self-efficacy, as a crucial predecessor of intrinsic motivation [19][20], was most predictive of the learning success. Numerous previous studies have suggested that a higher degree of self-efficacy leads to improved learning/training performance in digital learning environments, because it usually comes with a more positive attitude towards the learning content [60-62]. In other words, learners' perceived self-efficacy 
influences the attitude and ability to acquire new knowledge [63]. This is particularly important, as self-efficacy is an essential factor to increase learners' self-regulation in digital learning environments [64], and thereby promote self-regulated interaction with the new learning technology. Moreover, in the domain of learning mathematics self-efficacy is an important predictor of math related performance (e.g., [21-25]). Importantly, however, high math interest was not predictive for higher learning success. Instead, lower math interest was associated with more pronounced learning success. This might indicate that students with an already high interest in math and thereby high intrinsic motivation in doing mathematics might not benefit as much from the engaging effect of a game-based training approach as students with lower interest in mathematics. For the latter, the engaging nature of games may be particularly suitable to increase attention on the training content.

\subsection{Acceptance and intrinsic motivation predict flow}

Extending prior studies on flow experience, as a state of peak enjoyment and high quality of playing experience (e.g., [38][39]), and its relation to intrinsic motivation (e.g., [40][65][66]) as well as technology acceptance (e.g. [67-69]), the present study focused on whether the latter aspects were predictive of quality of playing experience (as operationalized as perceived flow). In particular, we hypothesized that higher intrinsic motivation, as assessed with math interest and math self-efficacy, as well as higher acceptance of the game as a learning tool should be accompanied by higher experience of flow (Hypothesis 3; see also Table 1).

The current results largely corroborated this hypothesis. In fact, we were able to predict large proportions of variance in users' perceived flow. In line with our expectations, we observed that higher math interest predicted higher states of perceived flow during learning with the game. Recently, intrinsic (math) interest was suggested to be one of three basic elements (besides absorption and enjoyment) composing flow (for a review see [70]). Our results lend empirical support to this suggestion. Moreover, as expected high flow was predicted by higher perceived usefulness and ease of use. Both of these predictors are not only key determinants of user technology adoption (e.g., [71-73]) but also seem to be highly relevant for the playing experience. This result emphasizes the crucial importance of basic variables of technology acceptance for the actual perception of high flow experience. Specifically the ease of use or controllability is often mentioned as a core factor of flow experience during learning (e.g., [74][75]). This also explains why the aspect "sense of control" is often included in the assessment of flow (see e.g. [38][53]), although this factor is usually defined more broadly and not restricted to ease of handling of a specific learning activity or task.

The multiple regression analysis also indicated that math self-efficacy and intention to use did not account for an additional unique part of the variance of flow. However, comparable to the case for the prediction of learning success these two variables were moderately correlated with students' experienced flow. Additionally, there were high correlations between math self-efficacy and math interest as well as between intention to use and perceived usefulness. In both cases, the variables seem to reflect predecessors of each other. In other words, self-efficacy increases interest in different scenarios [76-78]. Similar findings indicate that the rise of perceived usefulness positively affects the intention to use digital learning environments [61]. This might explain why only math interest and perceived usefulness did account for unique parts of variance in the multiple regression model.

\subsection{Limitations and Perspectives}

The present study yielded promising results regarding the importance of variables covering user acceptance and intrinsic motivation to predict learning success and users' experienced flow in a digital math game. Moreover, current results demonstrated that games can be used to increase students' rational number knowledge. However, there are some limitations that should be considered when planning future studies. First, in the current study we considered only a limited number of variables that might be relevant for assessing technology acceptance. In particular, user experience variables and other sociodemographic variables, such as aesthetics, involvement, novelty (e.g., [79]), enjoyment (e.g., [80]), gaming experience, gender (e.g., [32][81]) etc., should be addressed in future studies. New insights might also be gained by investigating user engagement more deeply, for instance, by using the User Engagement Scale [79]. This might not only help to better understand underlying mechanism of large-scale serious games adoption as well as extending other more complex models, such as the Unified Theory of Acceptance and Use of 
Technology [82]. Instead, it may also improve the prediction of learning success and flow experience by a more comprehensive set of variables. Importantly, however, the current study did not set out to evaluate or extend the TAM. Hence, we focused on most commonly reported critical variables of usage intentions and behavior to predict learning success and flow experience.

Another limitation of the current study is the restricted sample of students. For a more detailed analysis of TAM, flow experience or learning success, a larger sample size would be desirable. Apart from increasing statistical power, a larger sample size would allow for conducting more complex analyses, such as structural equation modeling, which might help to better understand underlying working mechanisms of learning success, flow experience, and serious games adoption. Moreover, due to the employed field testing in schools, our research design was restricted to the possibilities offered by the participating school classes, which led us to select only a limited set of variables to be examined in the current study. For instance, the limited time available in schools also was the reason why we decided to use single items only to assess perceived usefulness, intention to use, and perceived ease of use. This might have reduced validity and should be improved in future studies. The latter might benefit considerably from a more rigorous selection of variables, which may also reduce overall testing time in school. Despite these limitations, results from the present investigation extend the discussion on the successful use of games for learning mathematics by the identification of possible predictors of user experience and learning success

\subsection{Conclusions}

Recent evidence indicated that digital math games are an effective approach for improving students' learning. Going beyond previous studies, we investigated how individual variables critical to game-based learning influenced students' learning success. In particular, we investigated whether learning success in a game-based rational number training was predicted by students' acceptance of a game as a learning tool - in terms of its perceived usefulness, perceived ease of use, students' intention to use it - as well as their intrinsic motivation for math - in terms of their math interest and self-efficacy - and flow experience while playing. Additionally, we investigated the influence of the former variables on flow. Our results indicated that the game-based training was effective for improving rational number knowledge in sixth graders. Importantly, students' learning success was predicted by perceived usefulness of the game as a learning tool and ease of use, as well as math self-efficacy, math interest, and math grade. Moreover, students' experienced flow during playing was predicted by perceived usefulness as well as ease of use, and their math interest. Taken together, students' learning success and perceived flow seemed to be determined by their acceptance of a game as a learning tool and their intrinsic motivation for the respective learning domain. These results do not only have crucial implications for serious games research, but also for developers and practitioners applying and designing game-based learning environments. In particular, they suggest that games provide an effective learning approach but that it is important to consider learners prior knowledge and interest in the learning content as these may reduce the engaging effects of game-based learning when high (e.g., [83] for a review). Therefore, game-based learning might be particularly effective in low-performing students or students with low interest in the learning content.

\section{Acknowledgments}

The current research was funded by the Leibniz-Competition Fund (SAW) and the LeibnizWissenschaftsCampus "Cognitive Interfaces" supporting Manuel Ninaus (SAW-2016-IWM-3) and Academy of Finland (grant number 289140) supporting Kristian Kiili. Additionally, this research was funded by a grant from DFG (MO 2525/2-1) supporting Korbinian Moeller.

\section{References}

[1] Hainey, T., Connolly, T. M., Boyle, E. A., Wilson, A., \& Razak, A., “A systematic literature review of games-based learning empirical evidence in primary education," Computers \& Education, Vol. 102, pp. 202-223, November.2016. http://dx.doi.org/10.1016/j.compedu.2016.09.001. 
[2] Kiili, K., Devlin, K., \& Multisilta, J., "Editorial : Is game-based math learning finally coming of age?," International Journal of Serious Games, Vol. 2, No. 4, pp. 3-6, 2015. https://doi.org/10.17083/ijsg.v2i4.109

[3] Ninaus, M., Kiili, K., McMullen, J., \& Moeller, K., "Assessing fraction knowledge by a digital game," Computers in Human Behavior, Vol. 70, pp. 197-206, May.2017. http://dx.doi.org/10.1016/i.chb.2017.01.004

[4] Kiili, K. \& Ketamo, H., "Evaluating Cognitive and Affective Outcomes of a Digital GameBased Math Test," IEEE Transactions on Learning Technologies, 2017. https://doi.org/10.1109/TLT.2017.2687458

[5] Li, Q. \& Ma, X., "A meta-analysis of the effects of computer technology on school students' mathematics learning," Educational Psychology Review, Vol. 22, No. 3, pp. 215-243, 2010. http://dx.doi.org/10.1007/s10648-010-9125-8.

[6] Cohen Kadosh, R., Dowker, A., Heine, A., Kaufmann, L., \& Kucian, K., "Interventions for improving numerical abilities: Present and future," Trends in Neuroscience and Education, Vol. 2, No. 2, pp. 85-93, 2013. http://dx.doi.org/10.1016/j.tine.2013.04.001.

[7] Käser, T. et al., "Design and evaluation of the computer-based training program Calcularis for enhancing numerical cognition," Frontiers in Psychology, Vol. 4, No. AUG, pp. 1-13, 2013. http://dx.doi.org/10.3389/fpsyg.2013.00489.

[8] Wilson, A. J., Dehaene, S., Dubois, O., \& Fayol, M., "Effects of an adaptive game intervention on accessing number sense in low-socioeconomic-status kindergarten children," Mind, Brain, and Education, Vol. 3, No. 4, pp. 224-234, 2009. http://dx.doi.org/10.1111/j.1751-228X.2009.01075.x.

[9] Shin, N., Sutherland, L. M., Norris, C. A., \& Soloway, E., "Effects of game technology on elementary student learning in mathematics," British Journal of Educational Technology, Vol. 43, No. 4, pp. 540-560, 2012. http://dx.doi.org/10.1111/j.1467-8535.2011.01197.x.

[10]Ke, F., "A case study of computer gaming for math: Engaged learning from gameplay?," Computers \& Education, Vol. 51, No. 4, pp. 1609-1620, December.2008. http://dx.doi.org/10.1016/j.compedu.2008.03.003.

[11] Booth, J. L. \& Siegler, R. S., "Developmental and individual differences in pure numerical estimation.," Developmental psychology, Vol. 42, No. 1, pp. 189-201, 2006. http://dx.doi.org/10.1037/0012-1649.41.6.189.

[12] Fazio, L. K., Kennedy, C. A., \& Siegler, R. S., "Improving Children's Knowledge of Fraction Magnitudes," Plos One, Vol. 11, No. 10, p. e0165243, 2016. http://dx.doi.org/10.1371/journal.pone.0165243.

[13] Schneider, M. \& Stern, E., "The developmental relations between conceptual and procedural knowledge: a multimethod approach.," Developmental psychology, Vol. 46, No. 1, pp. 178192, 2010. http://dx.doi.org/10.1037/a0016701.

[14]Link, T., Nuerk, H.-C., \& Moeller, K., "On the relation between the mental number line and arithmetic competencies," The quarterly journal of experimental psychology, Vol. 67, No. 8, pp. 1597-1613, 2014. http://dx.doi.org/10.1080/17470218.2014.892517.

[15] Siegler, R. S., Fazio, L. K., Bailey, D. H., \& Zhou, X., "Fractions: The new frontier for theories of numerical development," Trends in Cognitive Sciences, Vol. 17, No. 1, pp. 13-19, 2013. http://dx.doi.org/10.1016/j.tics.2012.11.004.

[16] Chen, Z. H., Liao, C. C. Y., Cheng, H. N. H., Yeh, C. Y. C., \& Chan, T. W., "Influence of game quests on pupils' enjoyment and goal-pursuing in math learning," Educational Technology and Society, Vol. 15, No. 2, pp. 317-327, 2012.

[17]Lumsden, J., Skinner, A., Woods, A. T., Lawrence, N. S., \& Munafò, M., "The effects of gamelike features and test location on cognitive test performance and participant enjoyment," PeerJ, Vol. 4, p. e2184, 2016. http://dx.doi.org/10.7717/peerj.2184.

[18] Hamari, J., Koivisto, J., \& Sarsa, H., "Does gamification work? - A literature review of empirical studies on gamification," Proceedings of the Annual Hawaii International Conference on System Sciences, pp. 3025-3034, 2014. http://dx.doi.org/10.1109/HICSS.2014.377.

[19] Ryan, R. M. \& Deci, E. L., "Intrinsic and Extrinsic Motivations: Classic Definitions and New Directions.," Contemporary educational psychology, Vol. 25, No. 1, pp. 54-67, 2000. http://dx.doi.org/10.1006/ceps.1999.1020.

[20] Deci, E. L. \& Ryan, R. M., “The 'What' and 'Why' of Goal Pursuits: Human Needs and the Self-Determination of Behavior," Psychological Inquiry, Vol. 11, No. 4, pp. 227-268, 2000. http://dx.doi.org/10.1207/S15327965PLI1104_01.

[21] Skaalvik, E. M., Federici, R. A., \& Klassen, R. M., "Mathematics achievement and self- 
efficacy: Relations with motivation for mathematics," International Journal of Educational Research, Vol. 72, pp. 129-136, 2015. http://dx.doi.org/10.1016/j.ijer.2015.06.008.

[22]Peters, M. L., "Examining the relationships among classroom climate, self-efficacy, and achievement in undergraduate mathematics: A multi-level analysis," International Journal of Science and Mathematics Education, Vol. 11, No. 2, pp. 459-480, 2013. http://dx.doi.org/10.1007/s10763-012-9347-y.

[23] Reyes, L. H., "Affective Variables and Mathematics Education," The Elementary School Journal, Vol. 84, No. 5, pp. 558-581, 1984.

[24] Campbell, N. K. \& Hackett, G., "The effects of mathematics task performance on math selfefficacy and task interest," Journal of Vocational Behavior, Vol. 28, No. 2, pp. 149-162, 1986. http://dx.doi.org/10.1016/0001-8791(86)90048-5.

[25] Pajares, F. \& Miller, M. D., "Role of self-efficacy and self-concept beliefs in mathematical problem solving: A path analysis," Journal of Educational Psychology, Vol. 86, No. 2, pp. 193-203, 1994. http://dx.doi.org/10.1037/0022-0663.86.2.193.

[26] Boyle, E. A. et al., "An update to the systematic literature review of empirical evidence of the impacts and outcomes of computer games and serious games," Computers \& Education, Vol. 94, pp. 178-192, March.2016. http://dx.doi.org/10.1016/j.compedu.2015.11.003.

[27] Kenny, R. F. \& McDaniel, R., "The role teachers' expectations and value assessments of video games play in their adopting and integrating them into their classrooms," British Journal of Educational Technology, Vol. 42, No. 2, pp. 197-213, 2011. http://dx.doi.org/10.1111/j.14678535.2009.01007.x.

[28] Sandford, R., Ulicsak, M., Facer, K., \& Rudd, T., Teaching with games: Using commercial off-the-shelf computer games in formal education, Vol. 112. Bristol: Futurelab, 2006.

[29] Bourgonjon, J., De Grove, F., De Smet, C., Van Looy, J., Soetaert, R., \& Valcke, M., "Acceptance of game-based learning by secondary school teachers," Computers \& Education, Vol. 67, pp. 21-35, September.2013. http://dx.doi.org/10.1016/j.compedu.2013.02.010.

[30] Bourgonjon, J., Valcke, M., Soetaert, R., De Wever, B., \& Schellens, T., "Parental acceptance of digital game-based learning," Computers and Education, Vol. 57, No. 1, pp. 1434-1444, 2011. http://dx.doi.org/10.1016/j.compedu.2010.12.012.

[31] Rieber, L. P., "Seriously considering play: Designing interactive learning environments based on the blending of microworlds, simulations, and games," Educational Technology Research and Development, Vol. 44, No. 2, pp. 43-58, 1996. http://dx.doi.org/10.1007/BF02300540.

[32] Bourgonjon, J., Valcke, M., Soetaert, R., \& Schellens, T., "Students' perceptions about the use of video games in the classroom," Computers \& Education, Vol. 54, No. 4, pp. 1145-1156, May.2010. http://dx.doi.org/10.1016/j.compedu.2009.10.022.

[33] Davis, F. D., "Perceived Usefulness, Perceived Ease of Use, and User Acceptance of Information Technology," MIS Quarterly, Vol. 13, No. 3, p. 319, September.1989. http://dx.doi.org/10.2307/249008.

[34] Korostenskaja, M. et al., "Real-time functional mapping with electrocorticography in pediatric epilepsy: comparison with fMRI and ESM findings.," Clinical EEG and neuroscience, Vol. 45, No. 3, pp. 205-11, July.2014. http://dx.doi.org/10.1177/1550059413492960.

[35]Lee, Y.-H. H., Hsieh, Y.-C. C., \& Chen, Y.-H. H., “An investigation of employees' use of elearning systems: Applying the Technology Acceptance Model," Behaviour \& Information Technology, Vol. 32, No. 2, pp. 2013. http://dx.doi.org/10.1080/0144929X.2011.577190.

[36] Lee, Y. H., Hsiao, C., \& Purnomo, S. H., "An empirical examination of individual and system characteristics on enhancing e-learning acceptance," Australasian Journal of Educational Technology, Vol. 30, No. 5, pp. 562-579, 2014. https://doi.org/10.14742/ajet.381

[37] Shen, C. C. \& Chuang, H. M., "Exploring users' attitudes and intentions toward the interactive whiteboard technology environment," International Review on Computers and Software, Vol. 5, No. 2, pp. 200-208, 2010.

[38] Procci, K., Singer, A. R., Levy, K. R., \& Bowers, C., "Measuring the flow experience of gamers: An evaluation of the DFS-2," Computers in Human Behavior, Vol. 28, pp. 23062312, 2012. http://dx.doi.org/10.1016/j.chb.2012.06.039.

[39] Kiili, K., Lainema, T., de Freitas, S., \& Arnab, S., "Flow framework for analyzing the quality of educational games," Entertainment Computing, Vol. 5, No. 4, pp. 367-377, 2014. http://dx.doi.org/10.1016/j.entcom.2014.08.002.

[40] Csikszentmihalyi, M., Beyond boredom and anxiety. Jossey-Bass Publishers, 2000.

[41] Perttula, A., Kiili, K., Tuomi, P., \& Lindstedt, A., "Flow experience in game based learning a systematic literature review," International Journal of Serious Games, Vol 4,1, 2017, pp. 
57-72. https://doi.org/10.17083/ijsg.v4i1.151

[42] Pekrun, R., Goetz, T., Titz, W., \& Perry, R. P., Positive Emotions in Education, in Beyond Coping, Oxford University Press, 2002, pp. 149-174.

[43] Engeser, S. \& Rheinberg, F., "Flow, performance and moderators of challenge-skill balance," Motivation and Emotion, Vol. 32, No. 3, pp. 158-172, September.2008. http://dx.doi.org/10.1007/s11031-008-9102-4.

[44] Csikszentmihalyi, M., Flow: The Psychology of Optimal Experience, 2nd ed. New York: Harper \& Row, 2002.

[45] Ninaus, M., Pereira, G., Stefitz, R., Prada, R., Paiva, A., \& Wood, G., "Game elements improve performance in a working memory training task," International Journal of Serious Games, Vol. 2, No. 1, pp. 3-16, 2015. http://dx.doi.org/10.17083/ijsg.v2i1.60.

[46] Wouters, P., van Nimwegen, C., van Oostendorp, H., \& van der Spek, E. D., "A meta-analysis of the cognitive and motivational effects of serious games.," Journal of Educational Psychology, Vol. 105, No. 2, pp. 249-265, 2013. http://dx.doi.org/10.1037/a0031311.

[47] Lumsden, J., Edwards, E. A., Lawrence, N. S., Coyle, D., \& Munafò, M. R., "Gamification of Cognitive Assessment and Cognitive Training: A Systematic Review of Applications and Efficacy," JMIR Serious Games, Vol. 4, No. 2, p. e11, 2016. http://dx.doi.org/10.2196/games.5888.

[48] National Mathematics Advisory Panel, "Foundations for success: The final report of the National Mathematics Advisory Panel," Washington D.C., 2008.

[49] Bailey, D. H., Hoard, M. K., Nugent, L., \& Geary, D. C., "Competence with fractions predicts gains in mathematics achievement," Journal of Experimental Child Psychology, Vol. 113, No. 3, pp. 447-455, 2012. http://dx.doi.org/10.1016/j.jecp.2012.06.004.

[50] Booth, J. L. \& Newton, K. J., "Fractions: Could they really be the gatekeeper's doorman?," Contemporary Educational Psychology, Vol. 37, No. 4, pp. 247-253, 2012. http://dx.doi.org/10.1016/j.cedpsych.2012.07.001.

[51]Ninaus, M., Kiili, K., McMullen, J., \& Moeller, K., “A Game-Based Approach to Examining Students' Conceptual Knowledge of Fractions," in Proceedings of Games and Learning Alliance conference (GALA 2016) - Lecture Notes in Computer Science, 2016, Vol. 10056, pp. 37-49, http://dx.doi.org/10.1007/978-3-319-50182-6_4.

[52] Berger, J. L. \& Karabenick, S. A., "Motivation and students' use of learning strategies: Evidence of unidirectional effects in mathematics classrooms," Learning and Instruction, Vol. 21, No. 3, pp. 416-428, 2011. http://dx.doi.org/10.1016/j.learninstruc.2010.06.002.

[53]Rheinberg, F., Vollmeyer, R., \& Engeser, S., Die Erfassung des Flow-Erlebens [measuring flow-experience], in Diagnostik von Motivation und Selbstkonzept, Göttingen: Hogrefe, 2003, pp. 261-279.

[54]R Core Team, "R: A language and environment for statistical computing. R Foundation for Statistical Computing." Vienna, Austria, 2016.

[55] Wei, T. \& Simko, V., “corrplot: Visualization of a Correlation Matrix. R package version 0.77." 2016.

[56] Cohen, J., Statistical Power Analysis for the Behavioral Sciences, 2nd ed. New York, New York, USA: Lawrence Erlbaum Associates, 1988.

[57] Godden, D. R. \& Baddeley, A., "Context-Dependent Memory in Two Natural Environments: On Land and Underwater," British Journal of Psychology, Vol. 66, No. 3, pp. 325-331, August.1975. http://dx.doi.org/10.1111/j.2044-8295.1975.tb01468.x.

[58] Kettanurak, V., Ramamurthy, K., \& Haseman, W. D., "User attitude as a mediator of learning performance improvement in an interactive multimedia environment: an empirical investigation of the degree of interactivity and learning styles," International Journal of Human-Computer Studies, Vol. 54, pp. 541-583, 2001. http://dx.doi.org/10.1006/ijhc.2001.0457.

[59] Igbaria, M. \& Tan, M., "The consequences of information technology acceptance on subsequent individual performance," Information \& Management, Vol. 32, No. 3, pp. 113121, 1997. http://dx.doi.org/10.1016/S0378-7206(97)00006-2.

[60] Chu, R. J. \& Chu, A. Z., "Multi-level analysis of peer support, Internet self-efficacy and elearning outcomes - The contextual effects of collectivism and group potency," Computers and Education, Vol. 55, No. 1, pp. 145-154, 2010. http://dx.doi.org/10.1016/j.compedu.2009.12.011.

[61] Liaw, S. S., "Investigating students' perceived satisfaction, behavioral intention, and effectiveness of e-learning: A case study of the Blackboard system," Computers and Education, Vol. 51, No. 2, pp. 2008. 
http://dx.doi.org/10.1016/j.compedu.2007.09.005.

[62] Torkzadeh, G., Chang, J. C. J., \& Demirhan, D., "A contingency model of computer and Internet self-efficacy," Information \& Management, Vol. 43, No. 4, pp. 541-550, 2006. http://dx.doi.org/10.1016/j.im.2006.02.001.

[63] Liaw, S. S. \& Huang, H. M., "Perceived satisfaction, perceived usefulness and interactive learning environments as predictors to self-regulation in e-learning environments," Computers and Education, Vol. 60, No. 1, pp. 14-24, 2013. http://dx.doi.org/10.1016/j.compedu.2012.07.015.

[64] Sharma, S., Dick, G., Chin, W., \& Land, L., "Self-Regulation and E-Learning," in ECIS 2007 Proceedings, 2007.

[65] Garris, R., Ahlers, R., \& Driskell, J. E., "Games, Motivation, and Learning: A Research and Practice Model," Simulation \& Gaming, Vol. 33, No. 4, pp. 441-467, December.2002. http://dx.doi.org/10.1177/1046878102238607.

[66] Keller, J. \& Bless, H., "Flow and regulatory compatibility: an experimental approach to the flow model of intrinsic motivation.," Personality \& social psychology bulletin, Vol. 34, No. 2, pp. 196-209, February.2008. http://dx.doi.org/10.1177/0146167207310026.

[67]Hwang, G.-J., Wu, P.-H., \& Chen, C.-C., “An online game approach for improving students' learning performance in web-based problem-solving activities," Computers \& Education, Vol. 59, No. 4, pp. 1246-1256, 2012. http://dx.doi.org/10.1016/j.compedu.2012.05.009.

[68]Hsu, C.-L. \& Lu, H.-P., "Why do people play on-line games? An extended TAM with social influences and flow experience," Information \& Management, Vol. 41, No. 7, pp. 853-868, September.2004. http://dx.doi.org/10.1016/j.im.2003.08.014.

[69] Ghani, J. A., Flow in human-computer interactions: test of a model, in Human factors in management information systems: emerging theoretical bases, J. Carey, Ed. Norwood, NJ: Ablex Publishing Corp, 1995, pp. 291-311.

[70] Rodriguez-Sanchez, A. M., Schaufeli, W. B., Salanova, M., \& Cifre, E., "Flow experience among information and communication technology users," Psychological Reports, Vol. 102, pp. 29-39, 2008. http://dx.doi.org/10.2466/pro.102.1.29-39.

[71]Liu, S. \& Yuan, C., "Applying The Technology Acceptance Model and Flow Theory to Online E-Learning Users' Acceptance Behavior," International Association for Computer Information Systems, Vol. VI, No. 2, pp. 175-181, 2005. http://dx.doi.org/10.1108/09590550610660297.

[72] Tang, J. E. \& Chiang, C., "Towards an Understanding of the Behavioral Intention to Use Mobile Knowledge Management," WSEAS Transactions on Information Science and Application, Vol. 6, No. 9, pp. 1601-1613, 2009.

[73] Moon, J. W. \& Kim, Y. G., "Extending the TAM for a World-Wide-Web context," Information and Management, Vol. 38, No. 4, pp. 217-230, 2001. http://dx.doi.org/10.1016/S0378-7206(00)00061-6.

[74] Chen, H., Wigand, R. T., \& Nilan, M., "Exploring Web users' optimal flow experiences," Information Technology \& People, Vol. 13, No. 4, pp. 263-281, 2000. http://dx.doi.org/10.1108/09593840010359473.

[75] Wang, L. \& Chen, M., "The effects of game strategy and preference-matching on flow experience and programming performance in game-based learning," Innovations in Education and Teaching International, Vol. 47, No. 1, pp. 39-52, February.2010. http://dx.doi.org/10.1080/14703290903525838.

[76]Lent, R. W., Brown, S. D., \& Larkin, K. C., "Self-efficacy in the prediction of academic performance and perceived career options.," Journal of Counseling Psychology, Vol. 33, No. 3, pp. 265-269, 1986. http://dx.doi.org/10.1037/0022-0167.33.3.265.

[77]Lent, R. W., Brown, S. D., \& Hackett, G., "Toward a Unifying Social Cognitive Theory of Career and Academic Interest, Choice, and Performance," Journal of Vocational Behavior, Vol. 45, No. 1, pp. 79-122, 1994. http://dx.doi.org/10.1006/jvbe.1994.1027.

[78] Silvia, P. J., "Self-efficacy and interest: Experimental studies of optimal incompetence," Journal of Vocational Behavior, Vol. 62, No. 2, pp. 237-249, 2003. http://dx.doi.org/10.1016/S0001-8791(02)00013-1.

[79] Wiebe, E. N., Lamb, A., Hardy, M., \& Sharek, D., "Measuring engagement in video gamebased environments: Investigation of the User Engagement Scale," Computers in Human Behavior, Vol. 32, pp. 123-132, March.2014. http://dx.doi.org/10.1016/j.chb.2013.12.001.

[80]Fang, X. \& Zhao, F., "Personality and enjoyment of computer game play," Computers in Industry, Vol. 61, No. 4, pp. 342-349, 2010. http://dx.doi.org/10.1016/j.compind.2009.12.005.

[81] Procci, K., Bohnsack, J., \& Bowers, C., Patterns of Gaming Preferences and Serious Game 
pag. 30

Effectiveness, in Lecture Notes in Computer Science (including subseries Lecture Notes in Artificial Intelligence and Lecture Notes in Bioinformatics), Vol. 6774, No. PART 2, R. Shumaker, Ed. Berlin, Heidelberg: Springer Berlin Heidelberg, 2011, pp. 37-43.

[82] Ibrahim, R. \& Jaafar, A., "User Acceptance of Educational Games: A revised unified theory of acceptance and use of technology," International Journal of Social, Behavioral, Educational, Economic, Business and Industrial Engineering, Vol. 5, No. 5, pp. 557-563, 2011.

[83] Kalyuga, S., "Expertise reversal effect and its implications for learner-tailored instruction," Educational Psychology Review, Vol. 19, No. 4, pp. 509-539, 2007. http://dx.doi.org/10.1007/s10648-007-9054-3 